\title{
Induction of a Neural Phenotype in a Serotonergic Endocrine Cell Derived from the Neural Crest
}

\author{
J. M. Barasch, H. Mackey, H. Tamir, E. A. Nunez, and M. D. Gershon \\ Department of Anatomy and Cell Biology, Columbia University College of Physicians and Surgeons, and the Division of \\ Neuroscience, New York State Psychiatric Institute, New York, New York 10032
}

The thyroid parafollicular cell is an endocrine cell derived from the neural crest that stores 5-hydroxytryptamine (5-HT). In common with serotonergic neurons, but in contrast to 5-HTstoring cells that are not neurectodermal derivatives, parafollicular cells also contain a specific 5-HT binding protein. Despite this similarity to serotonergic neurons, parafollicular cells in situ were found to express an endocrine phenotype with few neural characteristics. Thus, the cells costore 5-HT with calcitonin, not calcitonin gene-related peptide (CGRP), which is the product of the calcitonin gene expressed in neurons, and they do not contain neurofilaments. The ability of adult parafollicular cells to respond to microenvironmental perturbations by expressing neuronal characteristics was examined. Sheep thyroid glands were dissociated, and parafollicular cells were purified by affinity chromatography. The purified parafollicular cells were grown in culture on a variety of substrates in the presence or absence of the $\beta$ subunit of nerve growth factor ( $\beta$-NGF). Parafollicular cells survived in culture for at least a week but retained a roughly spherical shape. Nevertheless, a subset of the cultured parafollicular cells began to display CGRP immunoreactivity. The addition of $\beta$-NGF to the cultured parafollicular cells induced a number of them to extend neurites and increased the proportion of cells in which CGRP immunoreactivity could be found. Neurite-bearing parafollicular cells appeared not to survive for more than $2 \mathrm{~d}$. While their survival was not enhanced when they were grown on collagen, polylysine, laminin, or reconstituted basal lamina, parafollicular cells that had extended neurites in response to $\beta$-NGF survived for at least a week when cocultured with an explant of aneuronal chick hindgut. The effect of the gut was local and only those neurite-bearing parafollicular cells that were growing in direct contact with the explant survived. The thyroid parafollicular cell therefore resembles another crest-derived endocrine cell, the adrenal chromatfin cell, in being able to manifest neural properties in culture. For the parafollicular cell these neural properties include the processing of RNA encoded by the calcitonin gene to express CGRP and neurite outgrowth in response to $\beta$-NGF.

\footnotetext{
Received Dec. 17, 1986; revised Mar. 20, 1987; accepted Mar. 25, 1987

This work was supported by NIH Grants AM 19743, NS 07062, NS 12969 and NS 15547, and NIMH Grant 37575.

Correspondence should be addressed to Dr. Gershon, Department of Anatomy and Cell Biology, Columbia University College of Physicians and Surgeons, 630 West 168 th Street, New York, NY 10032.

Copyright (C) 1987 Society for Neuroscience $0270-6474 / 87 / 092874-10 \$ 02.00 / 0$
}

Many different types of mature cell share an embryonic origin in the neural crest (Le Douarin, 1982). These include enteric glia (Rothman et al., 1986b), Schwann cells, peripheral neurons, pigment cells, and mesectodermal derivatives, which form the muscle of arterial walls, bone, and loose and dense connective tissue (Le Douarin, 1982; Noden, 1984). The crest also gives rise to endocrine cells-such as the chromaffin cells of the adrenal medulla (Le Douarin and Teillet, 1974), the glomus cells of the carotid body (Pearse et al., 1973), and the calcitoninsccreting cells of the ultimobranchial bodics (Le Douarin et al., 1974)-which, in mammals, become the parafollicular cells of the thyroid gland (Pearse, 1966; Bussolati and Pearse, 1967; Polak et al., 1974). These endocrine cells bear a variable relationship to neurons. Adrenal medullary chromaffin cells, for example, are directly innervated by sympathetic preganglionic axons, whereas there are no synapses on thyroid parafollicular cells; nevertheless, parafollicular cells resemble neurons and have been called paraneurons (Fujita, 1977). In particular, parafollicular cells, like central and enteric serotonergic neurons, are capable of synthesizing 5-HT from L-tryptophan (Nunez and Gershon, 1972). Moreover, again like the serotonergic neurons (Jonakait et al., 1977, 1979; Tamir and Gershon, 1979; Gershon et al., 1983a), parafollicular cells store 5-HT in subcellular storage organelles bound to a specific 5-HT binding protein (SBP) (Bernd et al., 1979, 1981; Barasch et al., 1987). This protein is not found in other 5-HT-storing cells, such as platelets, mast cells, or enteroendocrine cells, none of which is derived from neurectoderm (Gershon and Tamir, 1984). Because of its neuronlike properties, it has been suggested that the parafollicular cell can be used as a model for the study of serotonergic mechanisms relevant to neurons (Gershon and Tamir, 1984).

Factors that lead stem cells from the neural crest to realize their diverse potentialities are unknown. It has been noted that as these cells differentiate along their various lineages, there is a progressive narrowing of their developmental options (Le Douarin, 1982). Nevertheless, apparently mature endocrine cells of the adrenal medulla can be induced to assume a neuronal form when exposed to $\beta$-NGF (Unsicker et al., 1978, 1985a, b; Doupe et al., 1985). This conversion from endocrine to neural form is antagonized by glucocorticoids, high levels of which bathe the chromaffin cells in their natural location in the adrenal gland (Jones et al., 1977). As the chromaffin cells convert to neurons, they pass through intermediate forms that resemble type I SIF cells, another cell type that is also found in the sympathetic nervous system (Doupe et al., 1985). Thus, the endocrine derivatives of the neural crest may still be responsive to environmental signals and able to change their phenotype to that of a neuron even after they have exhibited their endocrine 
program. These data suggest that adrenal chromaffin cells, type I SIF cells, and sympathetic neurons may arise from a common type of progenitor cell, the fate of which is determined by the microenvironment in which these progenitors ultimately come to lie.

Precursors that migrate from the vagal region of the neural crest (adjacent to somites 1-7) give rise to serotonergic cells in both the gut and the thyroid gland in mammals or the ultimobranchial bodies in avians (Le Douarin, 1982; Rothman et al., 1986a). In the bowel the serotonergic cells are found in the myenteric plexus and are neurons, while in the thyroid they reside in follicles and assume an endocrine phenotype. Although the thyroid is both phylogenetically and embryologically a derivative of the gut (Ingbar, 1985), it presents a different microenvironment from that of the bowel proper to the crest cells that invade it. The presence of the same type of 5-HT binding protein, SBP, in both the neurons of the gut and the parafollicular cells of the thyroid suggests that a common precursor might have given rise to both of these serotonergic cell types. If so, then like adrenal medullary chromaffin cells, parafollicular cells might also be able to respond to environmental perturbations by expressing neural characteristics. The current experiments were undertaken in order to investigate this possibility. Neural properties were first examined in parafollicular cells of the intact thyroid gland. Parafollicular cells were then separated from suspensions of dissociated thyroid cells and grown in tissue culture. The ability of these cells to respond as neurons to changes in their microenvironment was determined. Neural properties that were studied included the ability to extend neurites in response to $\beta$-NGF and expression of calcitonin gene-related peptide (CGRP) as well as 5-HT. CGRP and calcitonin are both products of the calcitonin gene; however, the gene is transcribed differently in the thyroid and the nervous system (Amara et al., 1982; Rosenfeld et al., 1983). Alternative RNA processing results in the substantial expression of the CGRP coding exon but not that of calcitonin in the nervous system, while the exon coding for calcitonin is expressed preferentially in the thyroid (Grunditz et al., 1986).

\section{Materials and Methods}

Tissue culture. Sheep thyroid glands were dissociated at $37^{\circ} \mathrm{C}$ with $0.25 \%$ trypsin (Sigma Chemical Co., St. Louis, MO.) in Eagle's minimum essential medium with Earle's salts (MEM; Flow Laboratories, Rockville, MD.) supplemented with $1 \%$ BSA (Bernd et al., 1981). The medium also containcd antibiotics - $1 \%$ kanamycin (Gibco, Chagrin Falls, $\mathrm{OH}), 2 \%$ penicillin-streptomycin (Gibco)-in order to prevent the growth of bacteria and antimitotic agents $-10.0 \mu \mathrm{M}$ cytosine arabinoside (Sig$\mathrm{ma}$ ), $10.0 \mu \mathrm{M}$ fluorodeoxyuridine (Sigma), and $0.1 \mathrm{~mm}$ uridine (Sigma) to prevent the growth of yeast. The dissociation of the tissue was halted by the addition of soybean trypsin inhibitor (Sigma). The follicular cells in the resultant suspension ( $85 \%$ red blood cells, $13.5 \%$ follicular cells, and $1.5 \%$ parafollicular cells) were then made phagocytic by incubation with thyroid-stimulating hormone (TSH, $5 \mathrm{mU} / \mathrm{ml}$; Armour Pharmaceutical Co., Kankakee, IL) for $20 \mathrm{~min}$ at $37^{\circ} \mathrm{C}$. Following this incubation, the cells were loaded at $37^{\circ} \mathrm{C}$ onto an affinity column of Sepharose 6-MB beads (Pharmacia Fine Chemicals, Piscataway, NJ) coupled to thyroglobulin (Sigma). Follicular cells become bound to the column, while parafollicular cells pass through (Bernd et al., 1981). The clutcd cells were concentrated and separated from red cells, contaminants, and debris by brief centrifugation ( $10 \mathrm{~min}$ at $800 \times \mathrm{g}$ ) through $10 \%$ Ficoll (Pharmacia) in modified Eagle's medium (MEM). The purified parafollicular cells were diluted 5 -fold with MEM, pelleted $(800 \times$ $g$ for $15 \mathrm{~min}$ ) and resuspended in MEM supplemented with antibiotics as above (antimitotic agents were not included) but also containing $1 \%$ fetal bovine serum and $1 \%$ gentamycin. Parafollicular cells in this medium were then plated onto either uncoated $35 \mathrm{~mm}$ plastic dishes (Fal- con, Oxnard, CA) or onto glass coverslips coated with various substrates. Substrates included polylysine (Sigma), laminin (Collaborative Research Inc., Lexington, MA), reconstituted basal lamina material (Matrigel; Collaborative Research), or rat tail collagen polymerized with ammonia Coverslips were soaked in polylysine $(1 \mathrm{mg} / \mathrm{ml})$ for $24 \mathrm{hr}$, washed 5 times in sterile distilled water, and then rinsed in culture medium prior to use. Laminin $(2 \mu \mathrm{g} / \mathrm{ml})$ was added to washed polylysine-coated coverslips for $5 \mathrm{hr}$, following which the coverslips were briefly rinsed in culture medium. Matrigel was sterilely brushed onto coverslips at $4^{\circ} \mathrm{C}$ and polymerized at $37^{\circ} \mathrm{C}$ for $30 \mathrm{~min}$ in an atmosphere containing $5 \% \mathrm{CO}_{2}$. The phenol red present in the Matrigel was then washed out of the gel with MEM. Parafollicular cells were grown in culture at $37^{\circ} \mathrm{C}$ in an atmosphere containing $5 \% \mathrm{CO}_{2}$ for 1-7 d. In some experiments, cells were treated after a day's growth in culture with $50 \mathrm{ng} / \mathrm{ml}$ of the $\beta$-subunit of nerve growth factor ( $\beta$-NGF; Collaborative Research). In additional experiments, parafollicular cells were grown in a medium supplemented with a gut extract $(10 \%)$. The extract was prepared by passing $10 \mathrm{~d}$ chick embryonic gut (in $1 \mathrm{ml} \mathrm{MEM} /$ intestine) through a syringe fitted with a 22 gauge needle. The suspension was allowed to stand for $3 \mathrm{hr}$ at $4^{\circ} \mathrm{C}$ and was then centrifuged at $12,000 \times g$ for $30 \mathrm{~min}$. The supernatant was collected and stored at $-80^{\circ} \mathrm{C}$ until used.

Coculture of sheep parafollicular cells with chick hindgut. Chromatographically purified sheep parafollicular cells were suspended in an enriched medium. The enriched medium used in these coculture experiments contained MEM and antibiotics as above but was supplemented with $20 \%$ horse serum (Gibco), $10 \%$ chick embryo extract, and $\beta$-NGF $(50 \mathrm{ng} / \mathrm{ml})$. Chick embryo extract was prepared from white Leghorn chick embryos of $10 \mathrm{~d}$ incubation. Hindgut at the level of the cecal appendages was dissected in balanced salt solution from $4 \mathrm{~d}$ chick embryos. Explants $\left(\sim 0.5 \mathrm{~mm}^{3}\right)$ of the hindgut were placed on collagencoated glass coverslips and allowed to adhere under a thin film of enriched medium for $2 \mathrm{hr}$. Suspended parafollicular cells were then layered over the gut. Many of the parafollicular cells adhered to the explant of hindgut, while others flowed away from it to come to rest elsewhere on the culture dish. The cocultures were grown for 3 or $7 \mathrm{~d}$ at $37^{\circ} \mathrm{C}$ under an atmosphere that contained $5 \% \mathrm{CO}_{2}$. The culture medium was changed every second day.

Immunocytochemistry. Cultures were fixed with $4 \%$ formaldehyde (from paraformaldehyde) in $0.1 \mathrm{M} \mathrm{KPO}_{4}$ buffer ( $\mathrm{pH} 7.4$ ) containing $3 \%$ sucrose for $3 \mathrm{hr}$ at $4^{\circ} \mathrm{C}$. Whole thyroid glands were fixed by a modification of the 2-step procedure of Berod et al. (1981), in which tissues were initially fixed in a mixture of $4 \%$ formaldehyde (from paraformaldehyde) and $0.05 \%$ glutaraldehyde with $3.0 \%$ sucrose at $\mathrm{pH} 7.4$ for 20 min and then in $4 \%$ formaldehyde (from paraformaldehyde) with $3.0 \%$ sucrose in $0.1 \mathrm{M}$ borate buffer ( $\mathrm{pH} 9.5$ ) for $4 \mathrm{hr}$. Cultures were processed as whole mounts. Thyroid glands were cryoprotected with $30 \%$ sucrose in $0.1 \mathrm{M}$ PBS overnight, embedded in OCT (Miles Scientific, Naperville, IL), and frozen with liquid nitrogen. Frozen sections (6-12 $\mu \mathrm{m})$ were cut using a cryostat-microtome. The thyroid sections and whole mounts of cultures were permeabilized with $0.125 \%$ Triton-X 100 in $0.1 \mathrm{M}$ PBS $(30 \mathrm{~min})$ and then incubated with $10 \%$ horse serum in $0.1 \mathrm{M}$ Trisbuffered saline solution (TBS) with $0.125 \%$ Triton-X $100(30 \mathrm{~min})$ before application of a primary antibody. Primary antibodies included a rat monoclonal antibody to 5-IIT (1:200 or 1:400; Seralabs, Westbury, NY) (Costa et al., 1982), a rabbit antiserum to human calcitonin (1:200 or 1:400; Immunonuclear Corp., Stillwater, MN), a rabbit antiserum to human CGRP (1:2000; Peninsular Labs, Belmont, CA), or one of several immune reagents directed against components of the neurofilament triplet. These included the following mouse monoclonal antibodies: anti-200 kDa (Lab Systems, Helsinki, Finland); anti-200 kDa (kindly donated by Dr. John E. Wood, Welcome Research Labs., London, England; Wood and Anderton, 1981); anti-70 kDa (Sanbio, Nistelrode, Holland); anti-70 kDa, anti-150 kDa, and anti-200 kDa (BoehringerMannheim, Indianapolis); anti-150 kDa (Chemicon, El Segundo, CA); and phosphorylated 150-200 kDa (Sternberge-Meyer, Jarrettsville, MD). The following rabbit polyclonal antisera were also studied: anti-monkey 150 and $200 \mathrm{kDa}$ (kindly donated by Dr. Gudren Bennett of the University of Pennsylvania). These reagents were applied at $4^{\circ} \mathrm{C}$ overnight. Each immune reagent was diluted with $4 \%$ horse serum containing $0.125 \%$ Triton-X in TBS. The monoclonal antibodies to 5 -HT were localized using fluorescein isothiocyanate (FITC) or tetramethylrhodamine isothiocyanate (TRITC) coupled to goat anti-rat IgG and the calcitonin and CGRP antisera with FITC or TRITC coupled to goat anti-rabbit IgG. Secondary antibodies were obtained from Cappel (Malvern, PA), Kirkegaard and Perry (Gaithersburg, MD), and Miles-Yeda 

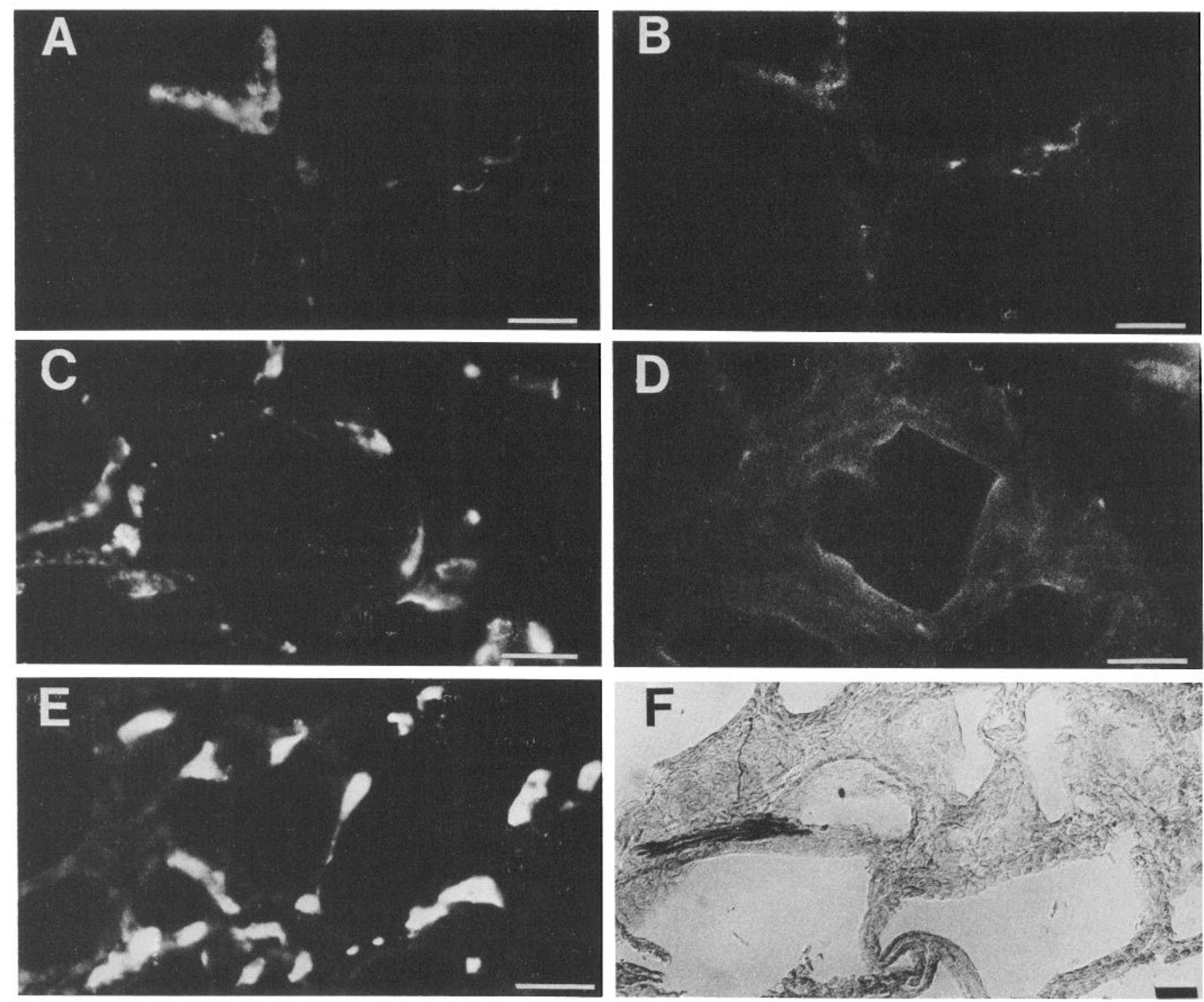

Figure 1. Immunocytochemical localization of 5-HT, calcitonin, CGRP, and phosphorylated 150/200 kDa neurofilament protein in frozen sections of the sheep thyroid gland. $A$ and $B$, Simultaneous demonstration of 5-HT and calcitonin immunoreactivity, respectively. Colocalization of the 2 substances was made possible by using primary antibodies raised in different species and species-specific secondary antisera coupled to TRITC (5-HT) or FITC (calcitonin). Immunoreactivity is seen in parafollicular cells, all of which contain both 5-HT and calcitonin. $C$ and $D$, Simultaneous demonstration of 5-HT and CGRP immunoreactivity with TRITC- and FITC-labeled secondary antisera, respectively. Parafollicular cells are identified by their 5 -HT immunofluorescence $(C)$; none contains demonstrable CGRP $(D)$. $E$, Some of the 5-HT immunofluorescent parafollicular cells display short processes. $F$, Neurofilament immunoreactivity (shown by immunoperoxidase reaction product) is found in nerves in the thyroid but not in parafollicular cells. Scale bars, $10 \mu \mathrm{m}$.

(Rehovot, Israel). Mouse primary antibodies were localized with biotinylated anti-mouse secondary antibodies (Kirkegaard and Perry), followed by application of streptavidin coupled to HRP (Kirkegaard and Perry). HRP was then visualized with $3,3^{\prime}$-diaminobenzidine and $\mathrm{H}_{2} \mathrm{O}_{2}$. $\mathrm{H}_{2} \mathrm{O}_{2}$ was generated with a glucose/glucose oxidase system (Itoh et al., 1979). Immunocytochemical controls included substitution of normal serum of the corresponding species for the primary antibodies or sera.

\section{Results}

\section{Immunocytochemical studies of thyroid glands}

The morphology and hormone content of sheep thyroid parafollicular cells were investigated immunocytochemically in frozen sections using a rabbit antiserum to calcitonin and a rat monoclonal antibody to 5-HT. The immunoreactive cells found with either reagent displayed a variety of shapes (Fig. 1). Most were compact, round to oval cells (Fig. 1, $A, B$ ), but others were more elongate, conforming to the contour of the basement membranes of thyroid follicles (Fig. $1 E$ ). Rare cells exhibited short, thick processes, but none of these processes were varicose or appeared to be neuritic. The colocalization of calcitonin and 5-HT immunoreactivities in every parafollicular cell of the intact sheep thyroid gland (Barasch et al., 1987) was confirmed in sections in which calcitonin and 5-HT were localized simultaneously (Fig. 1, $A, B$ ). Thus, prior to dissociation of the thyroid and growth of cells in vitro, either calcitonin or 5-HT immunoreactivity can serve as a marker for parafollicular cell identification. These antigens were therefore investigated along with 

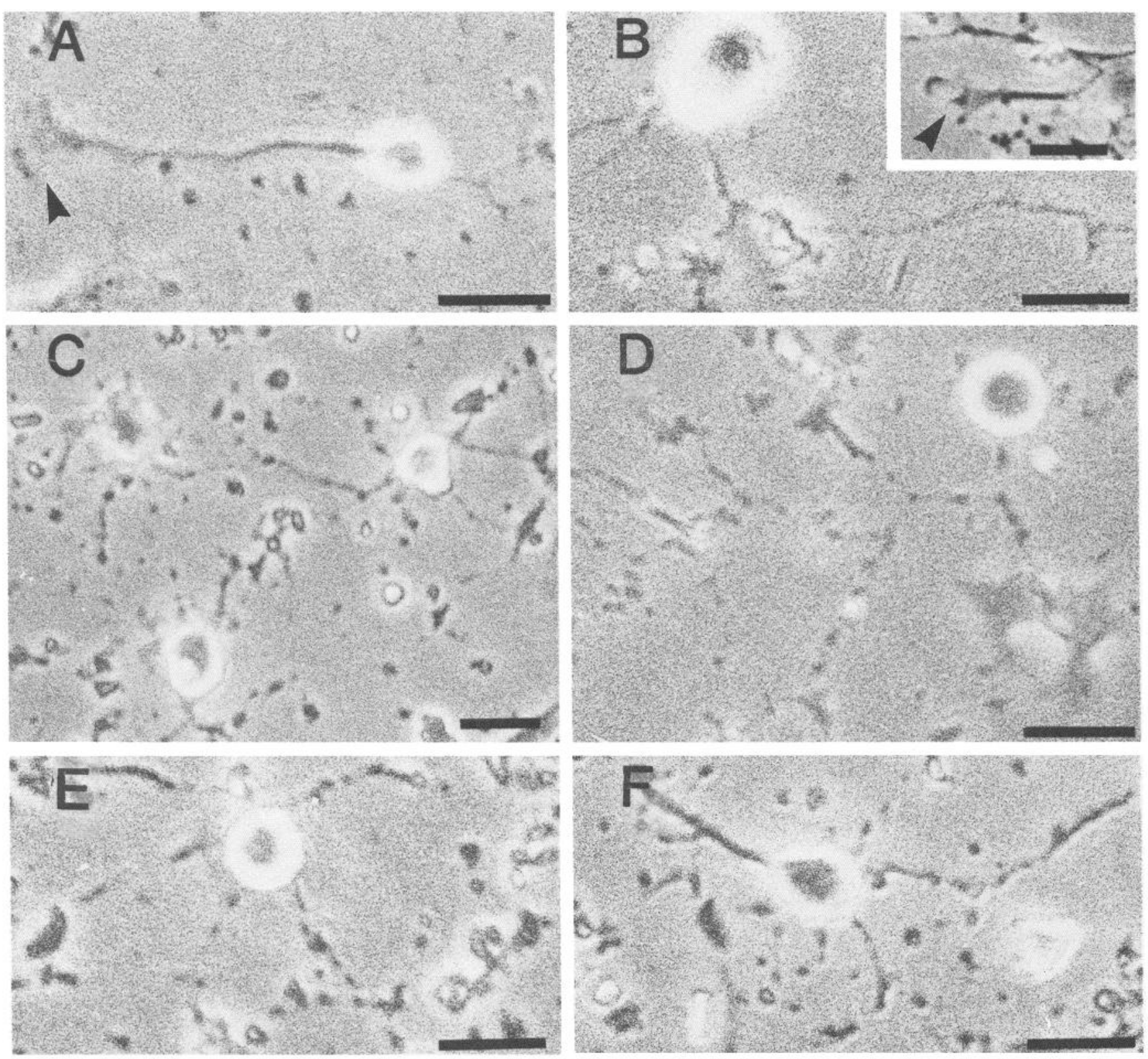

Figure 2. Effect of $\beta$-NGF on chromatographically purified parafollicular cells in culture. One day following addition of $\beta$-NGF to the culture medium, many of the cells have been induced to extend neurites. Typical cells are illustrated. Apparent growth cones can be seen at the ends of the neuritic extensions (arrowhead in $A$; inset in $B$ ). Processes were often varicose $(C-E)$ or branched $(D)$, and the neurite-bearing cells could be unipolar $(D)$, bipolar $(A, B)$, or multipolar $(C, E, F)$. Scale bars, $20 \mu \mathrm{m}$.

CGRP and neurofilament immunoreactivities in order to determine if these neural characteristics are expressed by parafollicular cells.

A number of fixation schedules, some of which are known to permit immunocytochemical visualization of CGRP in neurons of the PNS, were employed to search for thyroid CGRP (Rodrigo et al., 1985). When frozen sections of sheep thyroid were exposed to a rat monoclonal antibody to 5-HT and a rabbit antiCGRP serum, followed by species-specific secondary antibodies, none of the 5-HT immunoreactive cells showed CGRP immunoreactivity (Fig. 1, C, D). Demonstration of CGRP immunoreactivity in neurons of the gut served as a positive control (data not illustrated). In fact, antiserum to CGRP did not specifically react with any cell in the sheep thyroid. Immunocy- tochemistry was also used to search for neurofilament expression in the thyroid. No neurofilament immunoreactivity could be demonstrated in parafollicular cells with any of 8 different monoclonal antibodies or polyclonal antisera directed against the 70,150 , or $200 \mathrm{kDa}$ phosphorylated or nonphosphorylated components of the neurofilament triplet. In contrast, nerves in the thyroid were well stained by some of these reagents, especially by monoclonal antibodies that react with phosphorylated 200 and $150 \mathrm{kDa}$ components of neurofilaments (Fig. $1 F$ ).

\section{Effect of $\beta-N G F$ on parafollicular cells in vitro}

Purified parafollicular cells were obtained from preparations of trypsin-dissociated thyroid cells by affinity chromatography (Bernd et al., 1981; Barasch et al., 1987). About 97\% of the cells 

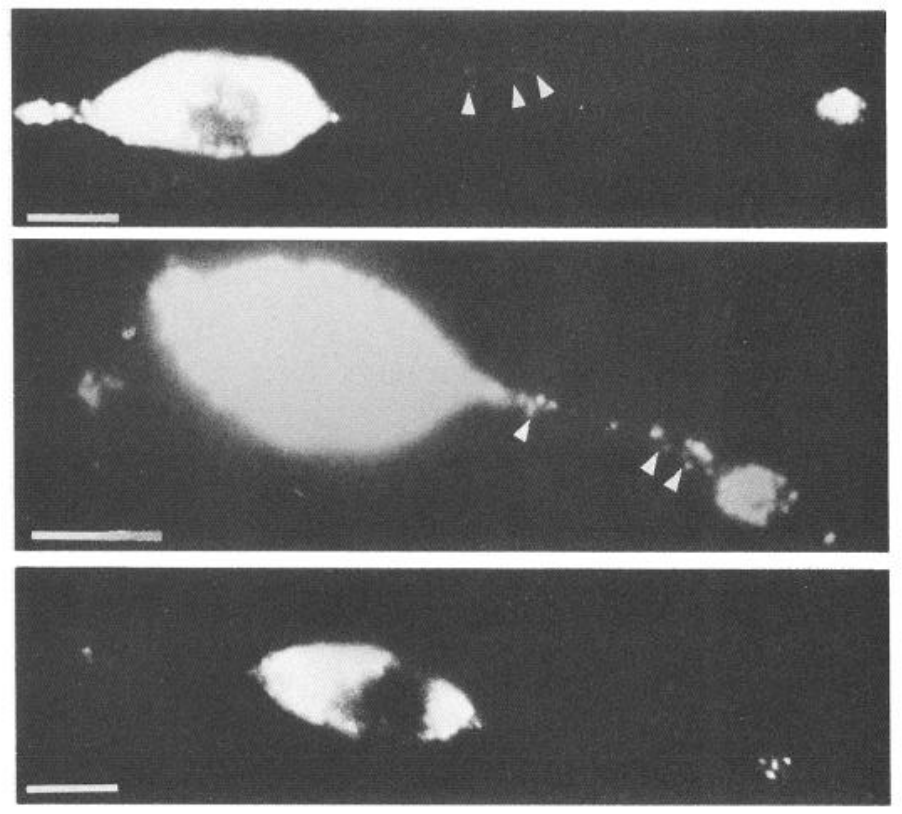

Figure 3. Immunofluorescence of calcitonin in cultured parafollicular cells that have been induced to extend neurites by the addition of $\beta$-NGF. Intense calcitonin immunofluorescence obscures detail in the perikarya of the parafollicular cells; however, small round immunofluorescent granules can be seen to have entered the neurites (arrowheads). The accumulation of granules with calcitonin immunoreactivity at the bulbous ends of the processes suggests a proximodistal translocation of the granules. Scale bars, $10 \mu \mathrm{m}$.

of this purified fraction are parafollicular (evaluated by electron microscopy) and about $85 \%$ of them, evaluated by trypan blue exclusion, are viable. Following their isolation, the purified parafollicular cells were plated and grown in culture. When initially plated, the parafollicular cells were roughly spherical in shape. This appearance was retained for up to a week when the cells were grown in vitro on plastic in a medium supplemented with $1 \%$ fetal bovine serum. A number of different substratesincluding laminin, polylysine, collagen, and reconstituted basal lamina material (Matrigel) - were employed to determine whether the parafollicular cells would extend neurites and/or preferentially adhere when grown on a material other than plastic. None of the substrates caused the parafollicular cells to extend neurites, but adherence of the cells was enhanced by growth on collagen and especially on Matrigel. (When grown on Matrigel, the cells were more flattened than they were when grown on plastic and, unlike cells grown on plastic, could not be dislodged from the substrate by vigorous shaking of the culture dish.) Parafollicular cells were also grown in a medium that was enriched with $20 \%$ horse serum and $10 \%$ chick embryo extract. Again, the approximately spherical morphology of parafollicular cells was retained.

In contrast to the absence of an effect of different substrates and media supplements on the morphology of the cultured parafollicular cells, addition of $50 \mathrm{ng} / \mathrm{ml} \beta$-NGF to the culture medium caused up to $8 \%$ of the cells to extend fine neuritic-appearing processes (Fig. 2). Most of the neurite-bearing cells were bipolar (Fig. 2A); however, several were multipolar and displayed as many as 6 varicose processes (Fig. 2, $C, E, F$ ), some of which were branched (Fig. $2 D$ ). The longest process of each cell grew to a length that ranged from 18 to $185 \mu \mathrm{m}$ (mean $=$ $49.4 \pm 7.7 \mu \mathrm{m} ; n=18)$ in $20 \mathrm{hr}$ and terminated in a fimbriated expansion that had the appearance of a growth cone (Fig. 2, A, $B$, inset). The morphology of the perikarya of the neurite-bearing cells did not change, remaining approximately spherical or elipsoidal, as neurites began to appear (Fig. 2, $D, E$; see also Fig. $4 A$ ). Calcitonin immunoreactivity was found in all of the cells from which processes had sprouted (Fig. 3). The presence of calcitonin immunoreactivity confirmed that the neurite-bearing cells were indeed parafollicular. Small, round calcitonin-immunofluorescent structures, about $0.4 \mu \mathrm{m}$ in diameter (Fig. 3), were found in the neuritic extensions of the parafollicular cells, indicating that secretory granules entered the processes. These granules became concentrated at or near the ends of the extensions so that calcitonin immunoreactivity was more intense at the terminals than along the shafts (Fig. 3).

Processes were seen on parafollicular cells both when NGF was added immediately following the initial plating of cells or when NGF was added after parafollicular cells had been established in culture for $2 \mathrm{~d}$. The elaboration of processes by parafollicular cells in response to $\beta$-NGF appeared to be independent of the substrate upon which the cells were grown. Thus, neuritic extension followed the addition of $\beta$-NGF, no matter whether parafollicular cells were cultured on plastic, laminin, polylysine, collagen, or Matrigel. In each case, parafollicular cell sprouting was seen $1 \mathrm{~d}$ after $\beta$-NGF was added to the cultures. The appearance of neurite-bearing cells, however, was transient. Two days after the addition of $\beta-\mathrm{NGF}$, no parafollicular cells with neuritic processes could be found on any of these substrates.

In order to test the hypothesis that a different microenvironment is required for the survival of parafollicular cells that sprout than for those that do not, we cocultured parafollicular cells with enteric mesenchyme. The enteric mesenchyme is a site in which the formation of neurons from precursor cells of neural crest origin normally occurs (Le Douarin, 1982; Rothman et al., 1986b). Hindgut was obtained from chick embryos at 4 $\mathrm{d}$ of incubation. The chick hindgut at this age has not been colonized by crest cells (Le Douarin, 1982); therefore, parafollicular cells can be grown on this tissue in the absence of endogenous neurons or other derivatives of the neural crest. Explants of $4 \mathrm{~d}$ chick hindgut were placed in culture and, after the explants had become adherent to the collagen-coated culture dishes, were overlain with an aliquot of chromatographically purified sheep parafollicular cells. Many of the parafollicular cells remained associated with the enteric explants, while others adhered to the collagen substrate elsewhere on the culture dish. Thus, controls for testing the effect of the gut on parafollicular cells included not only parafollicular cells grown by themselves on collagen, but also parafollicular cells grown in the same culture dish that were not in contact with the bowel. $\beta$-NGF was added to the cultures, and the parafollicular cells were examined $3 \mathrm{~d}$ and $7 \mathrm{~d}$ later. Immunocytochemical demonstration of 5-HT and calcitonin immunoreactivity permitted the identification of parafollicular cells. In contrast to the results obtained after $\beta$-NGF was added to parafollicular cells grown alone, parafollicular cells with neuritic processes were present at $3 \mathrm{~d}$ and $7 \mathrm{~d}$ following the addition of $\beta$-NGF to the cocultures of parafollicular cells with the chick hindgut (Fig. 4). Some $43 \%$ of those parafollicular cells that adhered to the bowel were neurite-bearing. In these coculture preparations all of the neurite-bearing parafollicular cells were found on the enteric explants; none of the control parafollicular cells, growing on the collagen substrate away from the bowel, exhibited processes. In fact, the majority of the neurite-bearing parafollicular cells were found in limited regions of 
the enteric explants, as if the bowel had specific zones that favored the persistence of these cells. The majority of the parafollicular cells within the explants of hindgut that extended neurites had 1 or 2 processes that terminated in bulbous expansions (Fig. 4A). 5-HT (Fig. 4A) and calcitonin (Fig. 4B) immunofluorescent granules entered these processes and accumulated in the expanded terminals. Moreover, even the parafollicular cells in the hindgut that did not sprout assumed fusiform or bottlelike shapes and spread to integrate themselves into the explanted tissue (Fig. 5). In most cases these nonsprouting parafollicular cells acquired shapes that followed the contour and pattern of their chick-derived neighbors. Most of the parafollicular cells in the hindgut that had put out processes contained both 5-HT and calcitonin immunoreactivity; however, these antigens were not colocalized in every parafollicular cell in the cocultures as they were in the sheep thyroid gland in vivo. Some cells were found that displayed only $5-\mathrm{HT}$, while others contained only calcitonin immunoreactivity; thus, under the culture conditions, on the chick gut, loss of expression either of 5-HT or calcitonin occurred in a subset of parafollicular cells. In additional experiments an extract was prepared from chick embryonic gut. Chromatographically purified parafollicular cells were grown with this extract (MEM supplemented with $10 \%$ gut extract and $1 \%$ fetal bovine serum) and treated with $\beta$-NGF in order to determine if the extract could substitute for an explant of gut to enhance the survival of neurite-bearing parafollicular cells. No neurite-bearing parafollicular cells could be seen after $3 \mathrm{~d}$ of culture in the presence of gut extract. It was concluded that the extract of gut could not substitute for an explant of enteric tissue.

The expression of CGRP immunoreactivity was cxamined in cultured parafollicular cells. The effect of $\beta$-NGF on this expression was investigated both on parafollicular cells grown alone and on parafollicular cells grown in cocultures with chick hindgut. The simultaneous demonstration of 5-HT immunoreactivity served as a parafollicular cell marker in these experiments. After $7 \mathrm{~d}$ in culture a subset $(40 \% ; n=1105$ cells) of 5 -HTimmunoreactive parafollicular cells expressed CGRP immunoreactivity. A small number of cells was also found that expressed CGRP immunoreactivity but not 5-HT. When $\beta$-NGF was added to cultures (for $7 \mathrm{~d}$ ), CGRP immunoreactivity was expressed in a higher proportion $(61 \% ; n=462$ cells; $p<0.001)$ of 5-HT-immunoreactive parafollicular cells. In the cocultures with chick hindgut, CGRP immunoreactivity was found to be present 3 and $7 \mathrm{~d}$ following the addition of $\beta$-NGF, in 5-HTimmunoreactive parafollicular cells that had entered the gut (Fig. 4, $C, D$ ), as well as in those that had not. Within the enteric explants, CGRP immunoreactivity was found in a subset $(50 \%)$ of the parafollicular cells that had extended neurites in response to $\beta$-NGF. Moreover, approximately half of all of the CGRPimmunoreactive parafollicular cells were neurite-bearing. Some of the CGRP-immunoreactive cells appeared to be losing their 5-HT immunoreactivity following growth on gut for $7 \mathrm{~d}$ in the presence of NGF (Fig. 4, $C, D$ ).

\section{Discussion}

Parafollicular cells in the intact sheep thyroid gland display a limited number of neural characteristics. The cells do contain 5-HT and SBP (Barasch et al., 1987); however, they do not extend neurites, and they do not display neurofilament immunoreactivity. Moreover, parafollicular cells preferentially express the exon of the calcitonin gene that codes for calcitonin
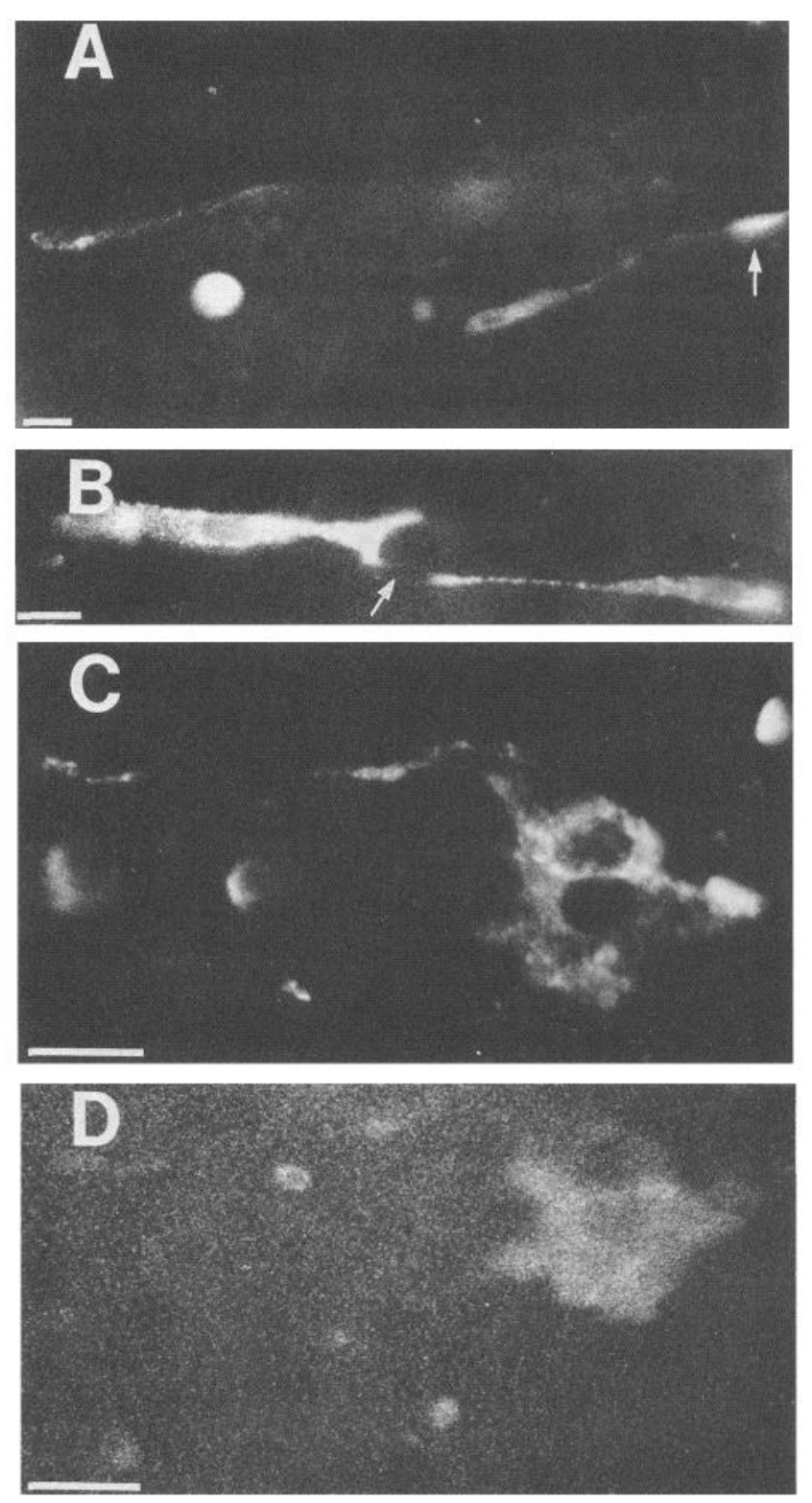

Figure 4. Immunofluorescence of 5-HT, calcitonin, and CGRP in cultured parafollicular cells that have been induced to extend neurites by the addition of $\beta$-NGF and that are growing on an explant of aneuronal chick hindgut. The parafollicular cells that have extended processes survived in this coculture for $7 \mathrm{~d}$. $A, 5-\mathrm{HT}$ immunofluorescence can be seen in the cell bodies and processes. Immunoreactive 5-HT has accumulated in an expanded end of a neurite (arrow). B. Calcitonin immunoreactivity. Note the immunofluorescence of granules in the processes of the parafollicular cells that appear to be terminating on another cell that is nonfluorescent (arrow). C, CGRP immunoreactivity. Two immunofluorescent parafollicular cells are in contact with one another. The upper cell has extended a neurite that passes out of the field to the left. $D, 5$-HT immunofluorescence. The same field is illustrated as shown in $C$. CGRP was visualized with a species-specific TRITC- and 5-HT with an FITC-labeled secondary antiserum. Note that although there is colocalization in both cells, the upper cell is strongly immunoreactive for CGRP but only weakly reactive for 5 -HT. Scale bars, $5 \mu \mathrm{m}$.

itself, rather than the exon that codes for CGRP. Although radioimmunoassays reveal CGRP-like immunoreactivity in rat and mouse thyroids (Lee et al., 1985; Grunditz et al., 1986), immunocytochemical observations have indicated that the material is not only found in parafollicular cells. A substantial 

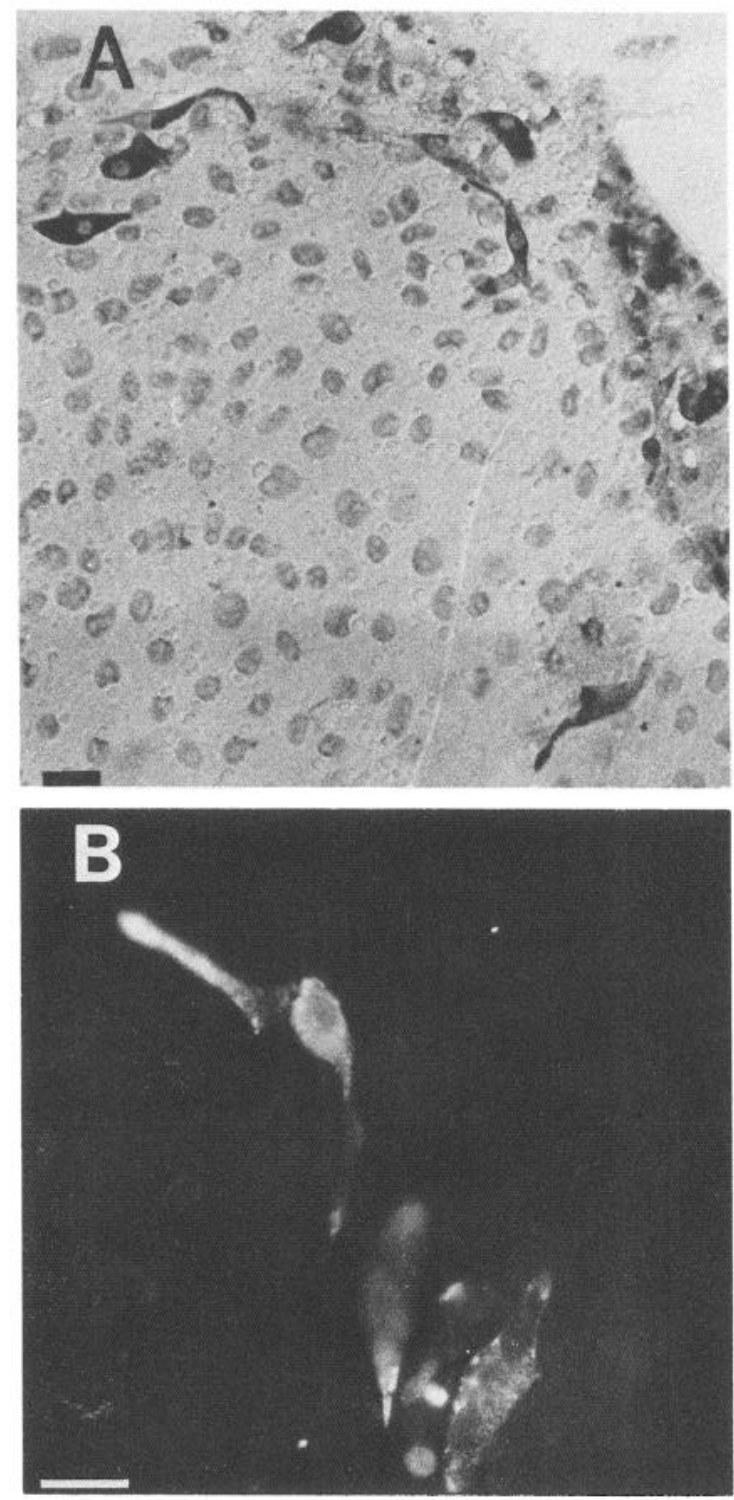

Figure 5. Immunoreactivity of 5-HT $(A)$ or calcitonin $(B)$ marks the location of cultured parafollicular cells that have been exposed to $\beta$-NGF and that are growing on an explant of aneuronal chick hindgut. Note that even those parafollicular cells that do not extend neurites have short processes and appear to have integrated themselves into the gut. Note that most of the parafollicular cells are located in one region of each explant. Scale bars, $10 \mu \mathrm{m}(A)$ and $5 \mu \mathrm{m}(B)$.

proportion of the CGRP immunoreactivity is present in afferent nerve fibers, where the peptide is costored with substance $P$ (Grunditz et al., 1986). In contrast to rat and mouse thyroid, little CGRP-like immunoreactivity can be detected in the thyroid glands of guinea pigs, calves, and sheep (Grunditz et al., 1986). Moreover, we could not demonstrate CGRP by immunocytochemistry in the 5-HT-containing parafollicular cells of the sheep thyroid gland, nor have other investigators been able to detect CGRP immunoreactivity or mRNA coding for CGRP in the rat thyroid (Rosenfeld et al., 1983). Thus, the endocrine characteristics of sheep parafollicular cells in situ are evident in the morphology of the cells, their intermediate filament content, and their processing of mRNA coded by the calcitonin gene to synthesize calcitonin.
In contrast to the endocrine phenotype of parafollicular cells in the intact thyroid gland, dissociated thyroid cells were found to express properties in vitro that are associated with neurons. Thus, a subset (about a third) of cultured parafollicular cells displayed CGRP immunoreactivity even while they retained a spherical profile. Since most of the cells that expressed CGRP immunoreactivity were in contact with other cells, which were fibroblastlike and did not contain 5-HT, it is possible that parafollicular cells express CGRP in vitro in response to the substrate or factors provided by these other cells. Indeed, the addition of $\beta$-NGF to the culture medium increased the proportion of cells in which CGRP immunoreactivity could be found. More strikingly, following the addition of $\beta$-NGF, some of the cultured parafollicular cells extended neurites. Since neurite-bearing parafollicular cells could be seen when NGF was added to cultures that had been established for $48 \mathrm{hr}$, which contained no neurite-bearing cells at the time, it is probable that NGF acted to induce the extension of neurites, rather than to promote the survival of a neurite-bearing subset of parafollicular cells. Furthermore, NGF does not enhance the survival of cells that have extended neurites. Quite the contrary, once cells have extended neurites following the addition of NGF their survival is compromised. The failure of NGF to promote survival also suggests that its action is to enhance expression of CGRP, not to promote the survival of CGRP-producing cells (which are not found in the sheep thyroid in situ). These observations indicate that cultured parafollicular cells, like sensory and sympathetic neurons (Levi-Montalcini and Angeletti, 1968; Thoenen and Barde, 1980), as well as adrenal chromaffin cells (Unsicker et al., 1978; Doupe et al., 1985), are responsive to $\beta$-NGF. Thyroid parafollicular cells, therefore, are like adrenal chromaffin cells in being endocrine cells that are able to manifest neural properties in culture. These neural properties include a probable increase in the processing of mRNA encoded by the calcitonin gene to express CGRP and neurite outgrowth in response to $\beta$-NGF. These observations thus expand the list of crest-derived cells known to be capable of responding to $\beta$-NGF to include those that contain 5-HT. The data also indicate that even noninnervated endocrine cells can respond like the innervated adrenal medullary and SIF cells to adopt neural characteristics.

It seems likely that the requirements of the derivatives of parafollicular cells for survival change once the cells extend neurites in response to $\beta-\mathrm{NGF}$. As a result, the neurite-bearing cells can be observed only transiently. We thus sought to determine if survival of parafollicular cells that have extended neurites would be enhanced if the cells were grown on another substrate or in a different microenvironment. For example, the neurite outgrowth induced by $\beta$-NGF in adrenal chromaffin cells is potentiated by factors, such as heart conditioned medium (Doupe et al., 1985) and ciliary neurotrophic factor (Unsicker et al., 1985b), that may adhere to appropriate substrates. Moreover, a number of conditioned media on adherent substrates also potentiate extension of neurites by neurons (Collins, 1978; Coughlin et al., 1981; Edgar and Thoenen, 1982; Lander et al., 1982). Since a variety of different substrates (plastic, collagen, polylysine, laminin, and Matrigel) and an enriched growth medium (20\% horse serum and 10\% chick embryo extract) failed to promote the survival of neurite-bearing cells in the continued presence of $\beta-\mathrm{NGF}$, the effect of another tissue was investigated. Because of the similarities between enteric serotonergic neurons and parafollicular cells, experiments were done with explants of aneuronal gut. Enteric serotonergic neurons, like the sero- 
tonergic parafollicular cells, are derived from precursors that originate in the vagal neural crest (Rothman et al., 1986b). These precursors differentiate into serotonergic neurons in vitro and survive well within enteric mesenchyme (Rothman and Gershon, 1982); therefore, we thought that the gut might provide a microenvironment that could support the survival of parafollicular cells that have been induced to express a neuronal phenotype.

A subset of the parafollicular cells that extended neurites in response to the addition of $\beta-N G F$, and which grew on the enteric mesenchyme, survived for at least 3 times as long as neurite-bearing parafollicular cells similarly exposed to $\beta$-NGF and grown on other substrates (plastic, collagen, polylysine, laminin, and Matrigel). This ability of explants of aneuronal bowel to enhance the survival of neurite-bearing parafollicular cells was remarkably local. Survival was not enhanced for any of the parafollicular cells that were plated in the same culture dish with explants of gut but that were not in direct contact with cells of the explant of bowel. Moreover, within the enteric explants, most of the surviving neurite-bearing parafollicular cells were restricted to limited regions, suggesting that there were preferential domains in the gut. Extracts of chick bowel could not substitute for explants in promoting survival of parafollicular cells with neuritic extensions. The sharply local nature of the phenomenon and the failure of extracts to mimic it suggest that the ability of the gut to promote the survival of parafollicular cells induced by $\beta$-NGF to sprout is not due to elaboration of a diffusible factor by the enteric mesenchyme. It may be a substrate effect or a response that requires direct cell-to-cell contact.

Choices made at branch points on developmental pathways by apparently undifferentiated cells may be predetermined at earlier stages or may result from the response of the cells to their microenvironment. Even when cells do respond to external factors, such as $\beta-N G F$, they must already have differentiated to the extent that they have acquired receptors or the capacity to respond to the external cues. Doupe et al. (1985) have proposed that pluripotent crest cells give rise to sympathetic neurons, type I SIF cells, and adrenal chromaffin cells. These progenitors are thought to be directed toward one or another of these end-stage cclls by the microenvironment in which they reside following their migration from the neural crest. The ability of $\beta$-NGF to convert adrenal chromaffin cells to cells with the morphology of type I SIF cells and then to neurons is seen as a manifestation of the residual responsiveness of an endocrine cell to a neural signal. Nevertheless, once the neural phenotype is acquired, the cells withdraw from the mitotic cycle and become, not only responsive to $\beta$-NGF, but unlike the chromaffin cell, dependent upon its presence. We would like to propose a similar developmental paradigm for the serotonergic crest derivatives that migrate to the gut and through the ultimobranchial bodies to the thyroid gland. We postulate that a common peripheral serotonergic precursor cell, analogous to the sympathoblast, arises in the neural crest. This cell is not necessarily pluripotent, but its developmental options include expression of either an endocrine or a neural phenotype. We further propose that this cell has acquired receptors for environmental stimuli that influence its choice of phenotype. The endocrine phenotype is favored in the ultimobranchial bodies, while the neuronal phenotype is favored in the gut.

$\beta-\mathrm{NGF}$ may or may not be a factor to which the serotonergic precursors of their derivatives respond under physiological circumstances. It is not yet known whether parafollicular cells respond to $\beta$-NGF in vivo or if they acquirc receptors as a function of their growth in vitro. Just as cultured parafollicular cells acquire the ability to express CGRP, so too they may acquire the ability to express $\beta$-NGF receptors. That trait may be a consequence of the cellular expression of neural characteristics, not its cause. Alternatively, it is possible that even in situ parafollicular cells do depend on $\beta$-NGF. In fact, Levi-Montalcini (1982) observed that when neonatal rats are sympathectomized by administration of antiserum to $\beta-\mathrm{NGF}$, they display hypothyroidism as well as a reduction in the volume of the thyroid gland. Although the cause of the hypothyroidism was not determined, the hypothyroidism may have resulted from damage to parafollicular cells by the anti- $\beta$-NGF treatment. Parafollicular cells are stimulated to secrete 5 -HT by TSH (Nunez and Gershon, 1983) and the released 5-HT acts as a paracrine hormone to induce the follicular cells to elaborate pseudopods (Nunez and Gershon, 1978). Furthermore, depletion of 5-HT reduces the response of follicular cells to TSH. Thus, if parafollicular cells within the thyroid gland are dependent on $\beta$-NGF, hypothyroidism might result from a loss of parafollicular cells or the loss of 5-HT from them. A requirement for parafollicular cell 5-HT may be particularly significant during the perinatal period, when the parafollicular cells of all mammals are rich in 5-HT (Gershon et al., 1971) and parafollicular cell secretion is active (Nunez and Gershon, 1976).

The gut is known to support neuronal survival. Even sympathetic postganglionic neurons that innervate mesenteric arteries and the enteric nervous system survive following a treatment of newborn rats with antiserum to $\beta$-NGF that destroys $99 \%$ of the sympathetic neurons of the paravertebral ganglia (Hill et al., 1985). This observation has been interpreted to indicate that there are 2 functionally distinct populations of sympathetic neurons that differ with respect to their sensitivity to the immunological removal of $\beta$-NGF. It is also possible that this differential ability to survive in the presence of antiserum to $\beta-\mathrm{NGF}$ is the result of the projections of surviving neurons to the bowel. Terminals of these survivors may gain access to an enteric source of growth factor, $\beta-\mathrm{NGF}$ or an analogous substance, that is not removed by administered anti- $\beta$-NGF. In fact, the enteric nervous system has been found to persist very well in animals exposed transplacentally to maternal antibody to $\beta$-NGF (Gershon et al., 1983b). It seems likely, therefore, that the neurons that colonize the gut to give rise to the enteric nervous system are subject in the bowel to a considerable influence of growth factor(s). The observation that the gut provides an environment in which parafollicular cells that have begun to express neuronal traits can survive is thus not surprising; however, the current experiments have not established that the enhancement of parafollicular cell survival is specific to the bowel. Moreover, the possibility also remains that the ability of the gut to support the survival of neurite-bearing parafollicular cells is developmentally regulated. The intestine used in the current experiments was removed prior to the arrival of host crest cells in the organ. Conceivably, following the arrival of large numbers of such cells, or in their presence, the effect of the bowel on parafollicular cell survival might be lost. It should also be pointed out that only relatively short periods of time were examined because of technical difficulties encountered in carrying out the experiments. Thus, the effects that were seen were not the complete conversion of parafollicular cells into neurons but the induction of neural characteristics in them. Even the cells that had extended neurites and that expressed the CGRP contained 
large peptide-filled granules that showed evidence of transport into the neurites of the neurite-bearing cells but that were not detectably replaced by the smaller synaptic vesicles characteristic of serotonergic and other neurons. This change, therefore, is reminiscent of the conversion of adrenal chromaffin cclls to type I SIF cells (Doupe et al., 1985). The hypothesis that parafollicular cells and enteric serotonergic neurons originate from a common type of crest-derived precursor cell is suggested but awaits confirmation. Nevertheless, the ability of parafollicular cells to display neural characteristics in vivo supports the view that what is learned from the study of serotonergic mechanisms in this model cell type may be relevant to serotonergic neurons.

\section{References}

Amara, S. G., V. Jonas, M. G. Rosenfeld, E. S. Ong, and R. M. Evans (1982) Alternate RNA processing in calcitonin gene expression generates mRNAs encoding different polypeptide products. Nature 298: 240-244.

Barasch, J. M., H. Tamir, E. A. Nunez, and M. D. Gershon (1987) Serotonin-storing secretory granules from thyroid parafollicular cells. J. Neurosci. (in press).

Bernd, P., M. D. Gershon, E. A. Nunez, and H. Tamir (1979) Localization of a highly specific neuronal protein, serotonin binding protein, in thyroid parafollicular cells. Anat. Rec. 193: 257-268.

Bernd, P., M. D. Gershon, F. A. Nunez, and H. Tamir (1981) Separation of dissociated thyroid follicular and parafollicular cells: Association of serotonin binding protein. J. Cell Biol. 88: 499-508.

Berod, A., B. K. Hartman, and J. F. Pujol (1981) Importance of fixation in immunohistochemistry: Use of formaldehyde solutions at variable $\mathrm{pH}$ for the localization of tyrosine hydroxylase. J. Histochem. Cytochem. 29: 844-850.

Bussolati, G., and A. G. E. Pearse (1967) Immunofluorescent localization of calcitonin in the C-cells of pig and dog thyroids. J. Endocrinol. 37: 205-209.

Collins, F. (1978) Induction of neurite outgrowth by a conditioned medium factor bound to the culture substratum. Proc. Natl. Acad. Sci. USA 75: 5210-5213.

Costa, M., J. B. Furness, A. C. Cuello, A. A. V. Verhofstad, H. W. J. Steinbusch, and R. P. Elde (1982) Neurons with 5-hydroxytryptamine-like immunoactivity in the enteric nervous systems: Their visualization and reactions to drug treatment. Neuroscience 4: 351364.

Coughlin, M. D., E. M. Bloom, and I. B. Black (1981) Characterization of a neuronal growth factor from mouse heart conditioned medium. Dev. Biol. 82: 56-68.

Doupe, A. J., S. C. Landis, and P. H. Patterson (1985) Environmental influences in the development of neural crest derivatives: Glucocorticoids, growth factors, and chromaffin cell plasticity. J. Neurosci. 5: 2119-2142.

Edgar, D., and H. Thoenen (1982) Modulation of NGF induced survival of chick sympathetic neurons by contact with a conditioned medium factor bound to culture substrate. Dev. Brain Res. 5: 89-92.

Fujita, T. (1977) Concept of paraneurons. Arch. Histol. Jpn. (Suppl.) 40: $1-12$.

Gershon, M. D., and H. Tamir (1984) Serotonectin and the family of proteins that bind serotonin. Biochem. Pharmacol. 33: 3115-3118.

Gershon, M. D., B. E. Belshaw, and E. A. Nunez (1971) Biochemical, histochemical and ultrastructural studies of thyroid serotonin, parafollicular and follicular cells during development in the dog. Am. J. Anat. 132: 5-20.

Gershon, M. D., K. P. Liu, S. E. Karpiak, and H. Tamir (1983a) Storage of serotonin in vivo as a complex with serotonin-binding protein in central and peripheral serotonergic neurons. J. Neurosci. 3: 1901-1911.

Gershon, M. D., T. P. Rothman, D. Sherman, and E. M. Johnson (1983b) Effect of prenatal exposure to anti-NGF on the enteric nervous system (ENS) of the guinea pig. Anat. Rec. 205: 62A.

Grunditz, T., R. Ekman, R. Hakanson, C. Rerup, F. Sundler, and R. Uddman (1986) Calcitonin gene related peptide in thyroid nerve fibers and C cells: Effects on thyroid hormone secretion and response to hyperglycemia. Endocrinology 119: 2313-2324.
Hill, C. E., I. A. Hendry, M. C. Ngu, and D. F. van Helden (1985) Subpopulations of sympathetic neurons differ in their sensitivity to ncrve growth factor antiserum. Dev. Brain Res. 23: 121-130.

Ingbar, S. (1985) The thyroid gland. In Williams' Textbook of Endocrinology, J. D. Wilson and D. W. Forster, eds., pp. 682-815, Saunders, Philadelphia, PA.

Itoh, K., A. Konishi, S. Nomura, N. Mizuno, Y. Nakamura, and T. Sugimoto (1979) Application of coupled oxidation reaction to electron microscopic demonstration of horseradish peroxidase: Cobaltglucose oxidase method. Brain Res. 175: 341-346.

Jonakait, J. M., H. Tamir, M. M. Rapport, and M. D. Gershon (1977) Detection of a soluble serotonin binding protein in mammalian myenteric plexus and other peripheral sites of serotonin storage. J. Neurochem. 28: 277-284.

Jonakait, J. M., H. Tamir, A. R. Gintzler, and M. D. Gershon (1979) Release of serotonin and its binding protein by enteric neurons. Brain Res. 174: 55-69.

Jones, M. T., E. W. Hillhouse, and J. L. Burden (1977) Dynamics and mechanisms of corticosteroid feedback at the hypothalamus and anterior pituitary gland. J. Endocrinol. 73: 405-417.

Lander, A. D., D. K. Fujii, D. Gospadarowicz, and L. F. Reichardt (1982) Characterization of a factor that promotes neurite outgrowth: Evidence linking activity to a heparan sulfate proteoglycan. J. Cell Biol. 94: 574-585.

Lee, Y., K. Takami, Y. Kawai, S. Girgis, C. J. Hillyard, I. MacIntyre, P. C. Emson, and M. Tohyama (1985) Distribution of calcitoningene related peptide in the rat peripheral nervous system with reference to its coexistence with substance P. Neuroscience 15: 12271237.

Le Douarin, N. (1982) The Neural Crest, Cambridge U. P., Cambridge, U.K.

Le Douarin, N. M., and M. A. Teillet (1974) Experimental analysis of the migration and differentiation of neuroblasts of the autonomic nervous system and of neurectodermal mesenchymal derivatives using a biological marker technique. Dev. Biol. 41: 162-184.

Le Douarin, N. M., J. Fontaine, and C. Le Lièvre (1974) New studies of the neural crest origin of the avian ultimo-branchial glandular cells. Interspecific combinations and cytochemical characterization of $\mathrm{C}$ cells based on the uptake of biogenic amine precursors. Histochemistry 38: 297-305.

Levi-Montalcini, R. (1982) Developmental neurobiology and the natural history of nerve growth factor. Annu. Rev. Neurosci. 5: 341362.

Levi-Montalcini, R., and P. U. Angeletti (1968) Nerve growth factor. Physiol. Rev. 48: 534-569.

Noden, D. M. (1984) The use of chimeras in analysis of craniofacial development. In Chimeras in Developmental Biology, N. Le Douarin and A. McLaren, eds., pp. 241-280, Academic, London.

Nunez, E. A., and M. D. Gershon (1972) Synthesis and storage of serotonin by parafollicular (C) cells of the thyroid gland of active, prehibernating and hibernating bats. Endocrinology 90: 1008-1024.

Nunez, E. A., and M. D. Gershon (1976) Secretion by parafollicular cells beginning at birth: Ultrastructural evidence from developing canine thyroid. Am. J. Anat. 147: 375-392.

Nunez, E. A., and M. D. Gershon (1978) Formation of apical pseudopods by canine thyroid follicular cells: Induction by thyrotropin and 5-hydroxytryptamine; antagonism by reserpine. Anat. Rec. 192: 215-261.

Nunez, E. A., and M. D. Gcrshon (1983) Thyrotropin induced thyroidal release of 5-hydroxytryptamine and accompanying ultrastructural changes in parafollicular cells. Endocrinology 113: 309-317.

Pearse, A. G. E. (1966) Common cytochemical properties of cells producing polypeptide hormones, with particular reference to calcitonin and the thyroid C cells. Vet. Rec. 79: 587-590.

Pearse A. G. E., J. M. Polak, F. W. D. Rost, J. Fontaine, C. Le Lièvre, and N. M. Le Douarin (1973) Demonstration of neural crest origin of type 1 (APUD) cells in the avian carotid body using a cytochemical marker system. Histochemistry 34: 191-203.

Polak, J. M., A. G. E. Pearse, C. Le Lièvre, J. Fontaine, and N. M. Le Douarin (1974) Immunocytochemical confirmation of the neural crest origin of avian calcitonin-producing cells. Histochemistry 40 : 209-214.

Rodrigo, J., J. M. Polak, L. Fcrnandcz, M. A. Ghatei, P. Mulderry, S. R. Bloom (1985) Calcitonin gene related peptide immunoreactive 
sensory and motor neurons of the rat, cat and monkey eosophagus. Gastroenterology 88: 444-451.

Rosenfeld, M. G., J. J. Mermod, S. G. Amara, L. W. Swanson, P. E Sawchenko, J. Rivier, W. Vale, and R. M. Evans (1983) Production of a novel neuropeptide encoded by the calcitonin gene via tissuespecific RNA processing. Nature 304: 129-135.

Rothman, T. P., and M. D. Gershon (1982) Phenotypic expression in the developing murine nervous system. J. Neurosci. 2: 381-393.

Rothman, T. P., D. Sherman, P. Cochard, and M. D. Gershon (1986a) Development of the monoaminergic innervation of the avian gut: Transient and permanent expression of phenotype markers. Dev. Biol. 116: 357-380.

Rothman, T. P., V. M. Tennyson, and M. D. Gershon (1986b) Colonization of the bowel by the precursors of enteric glia: Studies of normal and congenitally aganglionic mutant mice. J. Comp. Neurol. 252: 493-506.
Tamir, H., and M. D. Gershon (1979) Storage of serotonin and serotonin binding protein in synaptic vesicles. J. Neurochem. 33: 35-44.

Thoenen, H., and Y. A. Barde (1980) Physiology of nerve growth factor. Physiol. Rev. 60: 1285-1335.

Unsicker, K., B. Kirsch, U. Otten, and H. Thoenen (1978) Nerve growth factor-induced fiber outgrowth from isolated rat adrenal chromaffin cells: Impairment by glucocorticoids. Proc. Natl. Acad. Sci. USA 75: 3498-3502.

Unsickcr, K., S. D. Skaper, and S. Varon (1985a) Phenotypic changes of embryonic chick adrenal medullary cells in vitro induced by nerve growth factor and ciliary neuronotrophic factor. Neurosci. Lett. 60 : 127-132.

Unsicker, K., S. D. Skaper, and S. Varon (1985b) Neuronotrophic and neurite-promoting factors: Effects on early postnatal chromaffin cells from rat adrenal medulla. Dev. Brain Res. 17: 117-129. 